\title{
Feeding growth restricted preterm infants with abnormal antenatal Doppler results
}

\author{
J Dorling, S Kempley, A Leaf
}

Arch Dis Child Fetal Neonatal Ed 2005;90:F359-F363. doi: 10.1136/adc.2004.060350

Absence or reversal of end diastolic flow (AREDF) in the umbilical artery is associated with poor outcome, and elective premature delivery is common. Feeding these infants is a challenge. They often have poor tolerance of enteral feeding, and necrotising enterocolitis may develop. This review explores current practice to see if there is evidence on which to base guidelines. The incidence of necrotising enterocolitis is increased in infants with fetal AREDF, especially when complicated by fetal growth restriction. Abnormalities of splanchnic blood flow persist postnatally, with some recovery during the first week of life, providing justification for a delayed and careful introduction of enteral feeding. Such a policy exposes babies to the risks of parenteral nutrition, with no trials to date showing any benefit of delayed enteral nutrition. Trials are required to determine the optimum timing for introduction of enteral feeds in growth restricted infants with fetal AREDF.

See end of article for
authors' affiliations
$\ldots \ldots \ldots \ldots \ldots \ldots \ldots \ldots \ldots$
Correspondence to:
Dr Dorling, Department of
Health Sciences, University
of Leicester, Robert
Kilpatrick Clinical Sciences
Building, PO Box 65,
Leicester LE2 7LX, UK;
isd10@le.ac.uk
Accepted
26 February 2005

A ntenatal ultrasound with Doppler assessment of fetal blood flow velocities has made it possible to detect a population of fetuses with poor growth and abnormal circulation. Absence or reversal of end diastolic flow (AREDF) in the umbilical artery is associated with poor outcome, ${ }^{1}$ and thus elective premature delivery is common. Feeding these infants is a challenge: they are already under-nourished at birth and good nutrition and growth are essential. They often have poor tolerance of enteral feeding, and there is anxiety about development of necrotising enterocolitis (NEC). We set out to explore current practice and to determine whether there is evidence on which to base guidelines.

\section{CURRENT PRACTICE}

There is a lack of published information on current feeding practices for these infants. Recent surveys carried out in two English Health Regions (Southwest and Eastern) revealed considerable variations in practice. In the Southwest, enteral feeding was delayed in 9/12 hospitals for small for gestational age (SGA) babies <32 weeks gestation ("always" in three, "usually" in six), and "usually" in four hospitals for babies born at 32-36 weeks. Feeds were delayed for less than five days in five hospitals, more than five days in one hospital, and for a variable duration in five. Abnormal Doppler ultrasound results for fetal blood vessels, polycythaemia, presence of umbilical catheters, and absence of breast milk made delay more likely. Within the 15 hospitals in the Eastern Region, ${ }^{2}$ five units started feeds on day 1 , two delayed until day 7 , with the remainder starting feeds between day 2 and 5. The main reason cited for delaying feeds was to try to prevent NEC. Is this justified?

\section{WHICH INFANTS ARE AT INCREASED RISK OF NEC?}

Infants with intrauterine growth restriction (IUGR)

Early case-control studies of NEC tended to match cases with controls on the basis of birth weight. Many did not specifically evaluate IUGR as a risk factor, ${ }^{3}$ but even when they did, the marginal excess of SGA infants in the NEC cases was not statistically significant. ${ }^{4}$ Matching by birth weight may have led to the inclusion of similar numbers of SGA infants in the controls. More recent case-control studies which have matched controls by gestation have shown that IUGR may be a clinical risk factor for NEC. The case-control study by Beeby and Jeffrey ${ }^{5}$ of 82 infants with NEC revealed a different spectrum of associated factors for different gestational age groups: for babies of 30-36 weeks gestation, IUGR and markers of birth asphyxia were significant risk factors: odds ratio (OR) 6 (95\% confidence interval (CI) 1.3 to 26.8) for birth weight $<10$ th centile, and OR 9 (95\% CI 1.1 to 71) for birth weight $<3$ rd centile. For infants below 30 weeks gestation, formula milk feeding was a significant risk factor (OR 4, 95\% CI 1.1 to 14.1), but neither timing of first feed (3.1 $\mathrm{v}$ 2.5 days for controls) nor use of formula were significant factors for those born at 30-36 weeks. In an observational study of 69 cases of suspected or proven NEC, ${ }^{6} 49 \%$ of infants were SGA (birth weight $<10$ th centile), with $71 \%$ of those born at 30-36 weeks being SGA. Analysis of the effect of IUGR on outcome of 19759 singleton infants born at 25-30 weeks gestation and enrolled in the Vermont-Oxford Database revealed an increased risk of NEC when corrected for significant covariates (OR 1.27, 95\% CI 1.05 to 1.53$){ }^{7}$

Abbreviations: AREDF, absence or reversal of end diastolic flow; IUGR, intrauterine growth restriction; MEF, minimal enteral feeding; NEC, necrotising enterocolitis; SGA, small for gestational age; SMA, superior mesenteric artery 
The Santulli theory for pathogenesis of NEC involves a triad of ischaemia, bacteria, and substrate. ${ }^{8}$ The development of antenatal Doppler ultrasound of fetal blood vessels ${ }^{9}$ made it possible to study the fetal circulation, and reports soon appeared confirming that growth restricted fetuses often showed abnormal flow velocities in the descending aorta, with absence or even reversal of forward flow during diastole.

\section{Infants with abnormal antenatal Doppler studies}

In the IUGR fetus, hypoxaemia produces circulatory redistribution towards the brain and away from the viscera and placenta, culminating in umbilical artery or aortic AREDF in the most severely affected. There is little doubt that AREDF is associated with poor fetal outcome, but are these infants at increased risk of developing NEC once delivered?

We identified 14 unequivocally independent case series ${ }^{10-22}$ comparing NEC rates in infants who exhibited fetal AREDF with a control group (fig 1). Nine studies show an excess of NEC in the AREDF infants, with an overall OR for developing NEC of 2.13 (95\% CI 1.49 to 3.03 ) compared with controls with forward fetal end diastolic flow.

Eight studies classified NEC using the stricter definition of radiological or surgical confirmation, of which six showed an excess of confirmed NEC in the AREDF group. ${ }^{10-14}$ A large study by Kirsten et al ${ }^{15}$ showed the reverse pattern, but their study population was defined by maternal pregnancy induced hypertension, rather than suspected IUGR. Adiotomre et $\mathrm{al}^{21}$ had only one patient in each group with NEC. Overall, confirmed NEC was not significantly increased in these studies (OR 1.6, 95\% CI 0.9 to 2.8), but the six studies examining confirmed NEC in preterm infants with IUGR $^{1} 1011131421$ show greatly increased odds of confirmed NEC in infants with fetal AREDF (OR 6.9, 95\% CI 2.3 to 20)

In many studies, fetuses with AREDF required earlier delivery than controls. It could be argued that the higher risk of NEC in these studies was primarily related to the known risk factors of low gestation and birth weight. The excess of confirmed NEC was also found in the two series that matched controls for gestation and weight (OR 5.5, 95\% CI 1.1 to 28$).{ }^{11}$

\section{MECHANISMS OF INCREASED RISK OF NEC IN INFANTS WITH AREDF}

Several mechanisms, acting both before and after delivery, may explain the excess of NEC seen in growth restricted infants who exhibited fetal AREDF.

Abnormalities of the fetal mesenteric circulation have been shown to be part of brain sparing circulatory redistribution and AREDF. ${ }^{23}$ A combination of fetal hypoxia and increased mesenteric vascular resistance could produce hypoxic-ischaemic injury of the intestine or its mucosa before birth. Even if direct tissue injury does not occur, prolonged exposure to these conditions may modulate the development of motor, secretory, and mucosal function so that postnatally the intestine is more susceptible to stasis, abnormal colonisation, and bacterial invasion. Pseudo-obstruction has been documented in growth retarded infants, particularly in the presence of echogenic bowel and abnormal Doppler studies. ${ }^{24} 25$ Pregnancy induced hypertension with fetal growth restriction is also associated with neutropenia in early postnatal life, which may affect susceptibility to infective factors. ${ }^{26}$

After delivery, these infants are no longer hypoxic and it might be expected that any circulatory redistribution would rapidly resolve. However, postnatal physiological studies have shown persistent abnormalities in superior mesenteric artery (SMA) blood flow velocity in infants who experienced fetal AREDF. ${ }^{27-29}$ Both SMA and coeliac axis blood flow velocity are dramatically reduced on the first day of postnatal life. There is a slow recovery in baseline values during the first week of life, with SMA values at day 7 similar to those found in unfed appropriately grown infants. ${ }^{28} 29$ Despite this recovery in baseline SMA blood flow velocity values, the dynamic

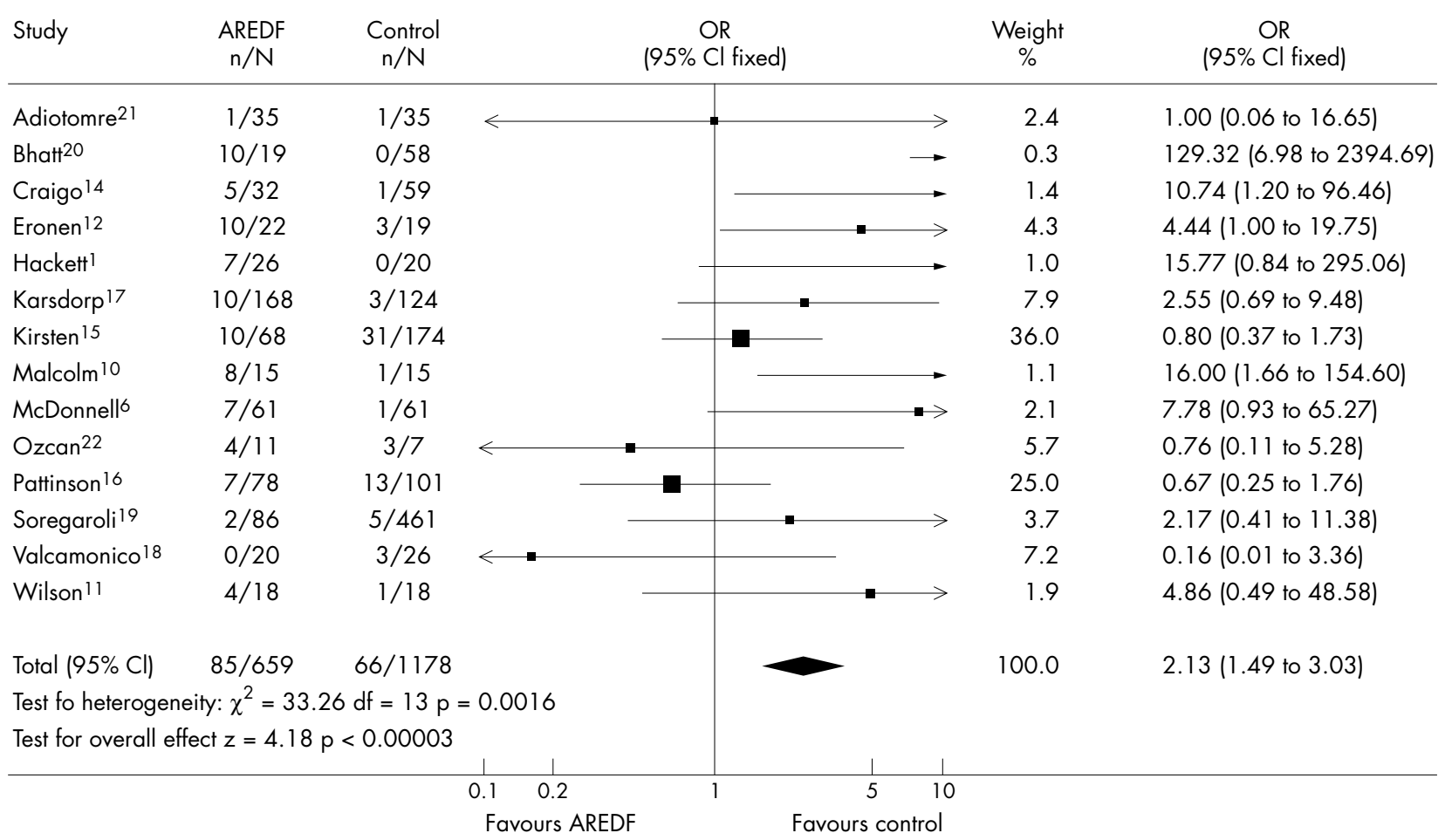

Figure 1 Studies comparing rates of necrotising enterocolitis (NEC) in fetuses with absent or reversed end diastolic flow (AREDF) in the umbilical artery or aorta, compared with controls who had forward end diastolic flow. Total number of cases of NEC (all grades, confirmed or unconfirmed) per live births in each group. The odds ratio (OR) and its $95 \%$ confidence interval (Cl) are given. 
response to the first enteral feed is still impaired in SGA infants. ${ }^{30}$

Experimental studies in animals show that hypoxia reduces intestinal blood flow and oxygen delivery through adrenergic vasoconstriction. ${ }^{31}$ Increased oxygen extraction can compensate for a $30 \%$ reduction in gut blood flow, ${ }^{32}$ but enteral feeding reduces the ability of oxygen extraction to compensate for the effects of hypoxia. ${ }^{33}$ The metabolic demands of enteral feeding increase oxygen consumption by the intestine. ${ }^{34}$

The combination of antenatal and persisting postnatal disturbances of gut perfusion, interacting with the metabolic demands of feeding, may adversely affect intestinal tissue oxygenation, combining with stasis and immunological factors to contribute to the development of NEC. In infants with AREDF, the recovery of parameters of intestinal perfusion during the first week provides a sound rationale for a modest delay in enteral feeding in these infants, to ensure that the metabolic stress of feeding is only imposed when baseline intestinal perfusion is as healthy as possible.

Data from the recently published GRIT study is reassuring with regard to the overall risk of NEC in infants with intrauterine growth failure, with only 30 of 587 infants (5.1\%) developing NEC. ${ }^{35}$ This study comprised fetuses with growth failure and abnormal Doppler studies, in which obstetricians were in a situation of equipoise over whether or not to deliver.

\section{CURRENT EVIDENCE ON FEEDING HIGH RISK INFANTS \\ Which milk to feed?}

In a large prospective randomised trial of early diet in preterm infants, Lucas and Cole ${ }^{36}$ identified a protective effect of breast milk on NEC (OR 10.6 (95\% CI 3.0 to 37.3) for confirmed cases and OR 3.5 (95\% CI 1.5 to 8.1) for all cases) and showed a protective effect of delaying onset of formula feeding $(p<0.05)$. Owing to the difficulty of recruiting infants to a randomised trial of human or formula milk when mothers have strong preferences, few trial data are available to confirm this. ${ }^{37}$

\section{When to start feeds? Early versus delayed feeding}

Although feeds are commonly delayed in high risk infants, there is little evidence that this approach is beneficial. A Cochrane review ${ }^{38}$ identified two small studies by Khayata et $a l^{39}$ and Davey et $a l^{40}$ in 72 preterm infants. Outcomes studied included days feedings held, weight gain, conjugated jaundice, NEC, and death. No statistically significant benefits were seen, and more studies are required to determine the optimal time of feed commencement.

Delaying feeds could be detrimental. Parenteral nutrition is usually used as an alternative source of carbohydrate, amino acids, and lipid, but side effects are common, especially catheter related sepsis, which occurs in up to $40 \%$ of preterm infants receiving parenteral nutrition through a percutaneous central catheter. ${ }^{41}{ }^{42}$ Other important side effects include cardiac tamponade, drug administration errors, cholestasis, osteopenia of prematurity, and metabolic complications. ${ }^{43-45}$

\section{Minimal enteral feeding}

An alternative approach to delaying feeds is to start small volumes of milk (10-20 ml/kg/day) and continue this for a period of time before advancing the volume of each feed. This approach, known as minimal enteral feeding (MEF) or trophic feeding, has recognised benefits, including enhanced endocrine and exocrine hormonal activity, improved growth of intestinal mucosa, and maturation of gut motility. ${ }^{46-48}$ Unfortunately, this approach has yet to be subjected to a large enough randomised trial to exclude a potential increase in the incidence of NEC. Tyson and Kennedy ${ }^{49}$ reviewed six studies of MEF compared with no feeding up to the third week of life in 397 preterm infants. Outcomes significantly affected by MEF were length of stay (weighted mean difference 15.6 days less stay in MEF group; 95\% CI 8.5 to 22.8 ) and days to full feeding (weighted mean difference 2.7 days less in MEF group; $95 \%$ CI 0.98 to 4.4 ).

Since this review was last updated in 1997, three further trials of MEF have been published. Van Ellburg et al ${ }^{50}$ studied 42 infants, seeing only one case of NEC in the unfed group. McClure and Newell ${ }^{51}$ studied 100 infants, seeing one and two cases of NEC in trophic and control infants respectively. The trial of Schanler et al ${ }^{52}$ contained 171 infants, with 13 cases of NEC in the trophic group, compared with 10 cases in the control infants. Combining these results with those of the meta-analysis of Tyson and Kennedy ${ }^{49}$, in 692 infants, NEC rates are similar at $10.5 \%$ for MEF and $9.4 \%$ for control infants (relative rate $1.07,95 \%$ CI 0.84 to 1.36). Further studies with adequate sample sizes are needed. If trophic feeding is shown to be safe with regard to NEC, substantial savings from reduced length of stay, use of parenteral nutrition, and episodes of septicaemia should be realised.

\section{How fast to advance the feeding volumes}

Data from retrospective studies have suggested that rapid advancement of feed volumes may increase the incidence of NEC, leading to a cautious approach by many clinicians. ${ }^{53} 54$ Trial data are reassuring, but relatively few patients (369) from three trials were included in the Cochrane review of feed advancement. ${ }^{55}$ In infants randomised to a faster increase in feed volumes, there was a reduction in days to full enteral feeding and days to regain birth weight, but no effect on NEC (relative risk 0.90, 95\% CI 0.46 to 1.77); further research is needed once again. Unfortunately the situation in extremely low birthweight infants is less clear, as only Rayyis et $a l^{56}$ included this population. A study published since this review $^{57}$ compared 15 and $30 \mathrm{ml} / \mathrm{kg} /$ day increments in 53 infants under $1250 \mathrm{~g}$ birth weight; two cases of NEC were seen in the faster advancement group. The only significant difference was a reduction in days to full feeding in the advancing group ( $10 \vee 14.8$ days). A recent trial comparing MEF with a regimen of advancing feeds in 141 infants born before 32 weeks gestation was stopped early as seven infants in the advancing group developed NEC compared with one control infant. ${ }^{58}$ The incidence of late onset sepsis and death were similar between the groups, with feed advancement leading to earlier establishment of feeds, reduced length of stay, and reduced use of parenteral nutrition. It is difficult to confidently generalise these results; the mean day of starting feeds was late in both groups at $9.3 v 10.3$ days, and fortifier was added when feeds reached $120 \mathrm{ml} / \mathrm{kg} /$ day and was doubled on reaching $140 \mathrm{ml} / \mathrm{kg} /$ day. In addition, feeds were given by a two hour infusion, followed by a two hour fast. These practices are not commonly used: feeds tend to be started earlier, given by continuous infusion or regular boluses without fasting, and fortifier is usually added to milk feeds when infants have reached $150 \mathrm{ml} / \mathrm{kg} /$ day. ${ }^{59}$

\section{SUMMARY AND CONCLUSIONS}

The incidence of NEC is increased in infants who exhibit fetal AREDF, especially when this is detected in pregnancies complicated by fetal growth restriction. The association of NEC with abnormal fetal Doppler studies is present even when compared with infants from pregnancies complicated by IUGR and when controlled for birth weight and gestation. Abnormalities of splanchnic blood flow persist postnatally, with some recovery during the first week of life, providing physiological justification for a delayed and careful introduction of enteral feeding. Such a policy exposes babies to the 
risks of parenteral nutrition, with no trials to date showing any benefit of delayed enteral nutrition. Trials are urgently required to determine the optimum timing for introduction of enteral feeds in the particular subgroup of growth restricted infants with fetal AREDF. This review is limited to looking at abnormal flow in the umbilical blood vessels, although other antenatal abnormalities of flow such as in the ductus venosus, cerebral arteries, or mesenteric arteries may also be important.

\section{ACKNOWLEDGEMENTS}

We gratefully acknowledge the funding of Action Medical Research for a forthcoming trial of the early or late introduction of feeds in preterm infants with abnormal antenatal Doppler studies.

\section{Authors' affiliations}

J S Dorling, Department of Health Sciences, University of Leicester, Leicester LE2 7LX, UK

S T Kempley, Barts and the London NHS Trust, Whitechapel, London El 1BB, UK

A Leaf, Neonatal Unit, Southmead Hospital, Westbury on Trym, Bristol BS10 5NB, UK

Competing interests: none declared

\section{REFERENCES}

1 Hackett GA, Campbell S, Gamsu H, et al. Doppler studies in the growth retarded fetus and prediction of neonatal necrotising enterocolitis, haemorrhage, and neonatal morbidity. Br Med J (Clin Res Ed) 1987;294: 13-16.

2 Dorling JS, McClure RJ. Survey of feeding practices for infants with AREDFV in the Eastern Region. Eastern Region Neonatal Conference, October, 1999.

3 Bunton GL, Durbin GM, Mcintosh N, et al. Necrotising enterocolitis. Arch Dis Child 1977;52:772-7.

4 Stoll B, Kanto WP, Glass RI, et al. Epidemiology of necrotizing enterocolitis: a case control study. J Pediatr 1980;96:447-51

5 Beeby PJ, Jeffrey H. Risk factors for nectrotising enterocolitis: the influence of gestational age. Arch Dis Child 1991;67:432-5.

6 McDonnell M, Wilkinson AR. Necrotising enterocolitis: perinatal approach to prevention, early diagnosis and management. Semin Neonato 1997;2:291-6.

7 Bernstein IM, Horbar JD, Badger GJ, et al. Morbidity and mortality among very-low-birthweight neonates with intrauterine growth restriction. Am J Obstet Gynecol 2000;182:198-206.

8 Santulli TV, Schullinger JN, Heird WC, et al. Acute necrotising enterocolitis in infancy: a review of 64 cases. Pediatrics 1975;55:376-87.

9 Gaziano EP. Antenatal ultrasound and fetal Doppler. Clin Perinatol 1995;22:111-39.

10 Malcolm G, Ellwood D, Devonald K, et al. Absent or reversed end-diastolic flow velocity in the umbilical artery and necrotising enterocolitis. Arch Dis Child 1991;66:805-7.

11 Wilson DC, Harper A, McClure G. Absent or reversed end-diastolic flow velocity in the umbilical artery and necrotising enterocolitis. Arch Dis Child 1991;66:1467

12 Eronen $M$, Kari A, Pesonen $E$, et al. Value of absent or retrograde enddiastolic flow in fetal aorta and umbilical artery as a predictor of perinatal outcome in pregnancy-induced hypertension. Acta Paediatr 1993;82:919-24.

13 McDonnell M, Serra-Serra V, Gaffney G, et al. Neonatal outcome after pregnancy complicated by abnormal velocity waveforms in the umbilical artery. Arch Dis Child 1994;70:F84-9.

14 Craigo SD, Beach ML, Harvey-Wilkes KB, et al. Ultrasound predictors of neonatal outcome in intrauterine growth restriction. Am J Perinatol 1996;13:465-71.

15 Kirsten GF, van Zyl N, Smith M, et al. Necrotizing enterocolitis in infants born to women with severe early preeclampsia and absent end-diastolic umbilica artery Doppler flow velocity waveforms. Am J Perinatol 1999;16:309-14.

16 Pattinson RC, Odendaal HJ, Kirsten G. The relationship between absent end diastolic velocities of the umbilical artery and perinatal mortality and morbidity. Early Hum Dev 1993;33:61-9.

17 Karsdorp VHM, van Vugt JMG, van Geijn HP, et al. Clinical significance of absent or reversed end diastolic velocity waveforms in umbilical artery. Lancet 1994;344:1664-8.

18 Valcamonico A, Danti L, Frusca T, et al. Absent end-diastolic velocity in umbilical artery: risk of neonatal morbidity and brain damage. Am J Obstet Gynecol 1994;170:796-801

19 Soregaroli M, Bonera R, Danti L, et al. Prognostic role of umbilical artery Doppler velocimetry in growth-restricted fetuses. J Matern Fetal Neonatal Med 2002;11:199-203.

20 Bhatt AB, Tank PD, Barmade KB, et al. Abnormal Doppler flow velocimetry in the growth restricted foetus as a predictor for necrotising enterocolitis. J Postgrad Med 2002;48:182-5.
21 Adiotomre PN, Johnstone FD, Laing IA. Effect of absent end diastolic flow velocity in the fetal umbilical artery on subsequent outcome. Arch Dis Child Fetal Neonatal Ed 1997;76:F35-8.

22 Ozcan T, Sbracia M, d'Ancona RL, et al. Arterial and venous Doppler velocimetry in the severely growth-restricted fetus and associations with adverse perinatal outcome. Ultrasound Obstet Gynecol 1998;12:39-44.

23 Korszun P, Dubiel $M$, Breborowicz $G$, et al. Fetal superior mesenteric artery blood flow velocimetry in normal and high-risk pregnancy. J Perinat Med 2002;30:235-41.

24 Blott M, Greenough A, Gamsu HR, et al. Antenatal factors associated with obstruction of the gastrointestinal tract by meconium. BMJ 1988;296:250.

25 Robel-Tillig E, Vogtmann C, Bennek J. Prenatal hemodynamic disturbances: pathophysiological background of intestinal motility disturbances in small for gestational age infants. Eur J Pediatr Surg 2002;12:175-9.

26 Davies N, Snijders R, Nicolaides KH. Intra-uterine starvation and fetal leucocyte count. Fetal Diagn Ther 1991:6:107-12.

27 Kempley ST, Gamsu HR, Vyas S, et al. Effects of intrauterine growth retardation on postnatal visceral and cerebral blood flow velocity. Arch Dis Child 1991;66:1115-18.

28 Gamsu HR, Kempley ST. Enteral hypoxia/ischaemia and necrotising enterocolitis. Semin Neonatal 1997;2:245-54.

29 Maruyama K, Koizumi T. Superior mesenteric artery blood flow velocity in small for gestational age infants of very low birth weight during the early neonatal period. J Perinat Med 2001;19:64-70.

30 Murdoch EM, Sinha AK, Kempley ST. Impaired splanchnic haemodynamic responses to enteral feeding in preterm growth restricted infants. Early Hum Dev 2003;73:93-109

31 Nowicki P, Caniano DA, Szaniszlo K. Effect of intestinal denervation on intestinal vascular response to severe arterial hypoxia in newborn swine. Am J Physiol 1988;254:G189-93.

32 Bulkley GB, Kvietys PR, Parks DA, et al. Relationship of blood flow and oxygen consumption to ischemic injury in the canine small intestine. Gastroenterology 1985;89:852-7.

33 Szabo JS, Mayfield SR, Oh W, et al. Postprandial gastrointestinal blood flow and oxygen consumption: effects of hypoxemia in neonatal piglets. Pediatr Res 1987;21:93-8.

34 Nowicki PT, Stonestreet BS, Hansen NB, et al. Gastrointestinal blood flow and oxygen consumption in awake newborn piglets: effect of feeding. Am J Physiol 1983;245:G697-702

35 GRIT Study Group. A randomised trial of timed delivery for the compromised preterm fetus: short term outcomes and Bayesian interpretation. $\mathrm{Br} J$ Obstet Gynaecol 2003;1 10:27-32.

36 Lucas A, Cole TJ. Breast milk and necrotising enterocolitis. Lancet 1990:336:1519-23.

37 Henderson G, Anthony MY, McGuire W. Formula milk versus preterm human milk for feeding preterm or low birth weight infants (Cochrane Review). Cochrane Library. Issue 3. Chichester: John Wiley \& Sons, 2004.

38 Kennedy KA, Tyson JE, Chamnanvanakii S. Early versus delayed initiation of progressive enteral feedings for parenterally fed low birth weight or preterm infants. Cochrane Database Syst Rev 2000;CD001970.

39 Khayata S, Gutcher G, Bamberger J, et al. Early versus late feeding of low birth weight (LBW) infants: effect on growth and hyperbilirubinemia [abstract]. Pediatr Res 1987;21:431A.

40 Davey AM, Wagner CL, Cox C, et al. Feeding premature infants while low umbilical artery catheters are in place: a prospective, randomized trial. J Pediatr 1994;124:795-9.

41 Trotter CW. Percutaneous central venous catheter-related sepsis in the neonate: an analysis of the literature from 1990 to 1994. Neonatal Netw 1996; 15:15-28.

42 Ainsworth SB, Furness J, Fenton AC. Randomized comparative trial between percutaneous longlines and peripheral cannulae in the delivery of neonatal parenteral nutrition. Acta Paediatr 2001;90:1016-20.

43 Camara D. Minimizing risks associated with peripherally inserted central catheters in the NICU. MCN Am J Matern Child Nurs 2001;26:17-21;quiz 22.

44 Heine RG, Bines JE. New approaches to parenteral nutrition in infants and children. J Paediatr Child Health 2002;38:433-7.

45 Meadows N. Monitoring and complications of parenteral nutrition. Nutrition $1998 ; 14: 806-8$.

46 Johnson CR. The trophic action of gastrointestinal hormones. Gastroenterology 1976;70:277-8.

47 Lucas A, Bloom R, Aynsley-Green A. Gut hormones and minimal enteral feeding. Acta Paediatr Scand 1986;75:719-23.

48 Berseth CL. Neonatal small intestinal motility: the motor responses to feeding in term and pretem infants. J Pediatr 1990;117:777-82.

49 Tyson JE, Kennedy KA. Minimal enteral nutrition for promoting feeding tolerance and preventing morbidity in parenterally fed infants. Cochrane Database Syst Rev 2000;(2):CD000504.

50 van Elburg RM, van den Berg A, Bunkers CM, et al. Minimal enteral feeding, fetal blood flow pulsatility, and postnatal intestinal permeability in preterm infants with intrauterine growth retardation. Arch Dis Child Fetal Neonatal Ed 2004;89:F293-6.

51 McClure RJ, Newell SJ. Randomised controlled study of clinical outcome following trophic feeding. Arch Dis Child Fetal Neonatal Ed 2000;82:F29-33.

52 Schanler RJ, Shulman RJ, Lau C, et al. Feeding strategies for premature infants: randomized trial of gastrointestinal priming and tube-feeding method. Pediatrics 1999; 103:434-9.

53 Brown EG, Sweet AY. Preventing necrotizing enterocolitis in neonates. JAMA $1978 ; 240: 2452-4$ 
54 Uauy RD, Fanaroff AA, Korones SB, et al. Necrotizing enterocolitis in very low birth weight infants: biodemographic and clinical correlates. J Pediatr 1991;119:630-8.

55 Kennedy KA, Tyson JE, Chamnanvanakij S. Rapid versus slow rate of advancement of feedings for promoting growth and preventing necrotizing enterocolitis in parenterally fed low-birth-weight infants (Cochrane Review). Cochrane Library. Issue 3. Chichester: John Wiley \& Sons, 2004.

56 Rayyis SF, Ambalavanan N, Wright L, et al. Randomized trial of "slow" versus "fast" feed advancements on the incidence of necrotizing enterocolitis in very low birth weight infants. J Pediatr 1999;134:293-7.
57 Salhotra A, Ramji S. Slow versus fast enteral feed advancements in very low birth weight infants: a randomized controlled trial. Indian Pediatr 2004;41:435-41.

58 Berseth CL, Bisquera, JA, Paje, VU. Prolonging small feeding volumes early in life decreases the incidence of necrotizing enterocolitis in very low birth weight infants. Pediatrics 2003;111: 529-34

59 Kuschel CA, Harding JE. Multicomponent fortified human milk for promoting growth in preterm infants (Cochrane Review). Cochrane Library. Issue 3. Chichester: John Wiley \& Sons, 2004.

\section{Clinical Evidence-Call for contributors}

Clinical Evidence is a regularly updated evidence-based journal available worldwide both as a paper version and on the internet. Clinical Evidence needs to recruit a number of new contributors. Contributors are healthcare professionals or epidemiologists with experience in evidence-based medicine and the ability to write in a concise and structured way.

Areas for which we are currently seeking authors:

- Child health: nocturnal enuresis

- Eye disorders: bacterial conjunctivitis

- Male health: prostate cancer (metastatic)

- Women's health: pre-menstrual syndrome; pyelonephritis in non-pregnant women

However, we are always looking for others, so do not let this list discourage you.

Being a contributor involves:

- Selecting from a validated, screened search (performed by in-house Information Specialists) epidemiologically sound studies for inclusion.

- Documenting your decisions about which studies to include on an inclusion and exclusion form, which we keep on file.

- Writing the text to a highly structured template (about 1500-3000 words), using evidence from the final studies chosen, within 8-10 weeks of receiving the literature search.

- Working with Clinical Evidence editors to ensure that the final text meets epidemiological and style standards.

- Updating the text every six months using any new, sound evidence that becomes available. The Clinical Evidence in-house team will conduct the searches for contributors; your task is simply to filter out high quality studies and incorporate them in the existing text.

- To expand the topic to include a new question about once every 12-18 months.

If you would like to become a contributor for Clinical Evidence or require more information about what this involves please send your contact details and a copy of your CV, clearly stating the clinical area you are interested in, to Klara Brunnhuber (kbrunnhuber@ bmigroup.com).

\section{Call for peer reviewers}

Clinical Evidence also needs to recruit a number of new peer reviewers specifically with an interest in the clinical areas stated above, and also others related to general practice. Peer reviewers are healthcare professionals or epidemiologists with experience in evidence-based medicine. As a peer reviewer you would be asked for your views on the clinical relevance, validity, and accessibility of specific topics within the journal, and their usefulness to the intended audience (international generalists and healthcare professionals, possibly with limited statistical knowledge). Topics are usually 1500-3000 words in length and we would ask you to review between $2-5$ topics per year. The peer review process takes place throughout the year, and our turnaround time for each review is ideally 10-14 days.

If you are interested in becoming a peer reviewer for Clinical Evidence, please complete the peer review questionnaire at www.clinicalevidence.com or contact Klara Brunnhuber (kbrunnhuber@bmigroup.com). 